\title{
PERBEDAAN PENDAPATAN DAN KELAYAKAN USAHATANI PADI VARIETAS INPARI 32 DAN VARIETAS INPARI 42
}

\author{
Saparto'), Ahimzha Ibnu Wiharnata'2), Sumardi3) \\ 1) STIP Farming Semarang, JI. Pawiyatan Luhur IV/15 Bendan Duwur, Semarang, Hp: 089654173707 , \\ 2) Lab. Pengamatan Hama Penyakit Tanaman Jl. Sidokerto Rendole Indah, Winong-Kabupaten Pati \\ 3) STIP Farming Semarang, JI. Pawiyatan Luhur IV/15 Bendan Duwur, Semarang \\ email : saparto.saparto@gmail.com
}

\begin{abstract}
Abstrak
Penelitian ini bertujuan untuk mengetahui pendapatan dan kelayakan usahatani padi varietas Inpari 32 dan varietas Inpari 42. Penelitian dilakukan di Desa Kutoharjo, Kecamatan Pati, Kabupaten Pati mulai Mei 2019Pebruari 2020. Metode penelitian yang digunakan adalah survei. Metode pengambilan sampel menggunakan Stratified Random Sampling dan diperoleh sampel 35 responden petani yang menggunakan varietas Inpari 32, dan 35 responden petani yang menggunakan 42 . Variabel yang dihitung meliputi biaya benih, pupuk, pestisida, dan tenaga kerja serta hasil produksi gabah. Data dianalisis menggunakan rumus matematika untuk pendapatan dan kelayakan, dan uji-t untuk perbedaan rata-rata pendapatan. Hasil penelitian : Pendapatan usahatani padi varietas Inpari 32 sangat berbeda nyata $(P<1 \%)$ lebih tinggi dibanding padi varietas Inpari 42. Usahatani padi varietas Inpari 32 : pendapatan = Rp. 11.253.124,-/ha; R/C $=1,76 ; \mathrm{BEP}(\mathrm{Rp})=\mathrm{Rp} .2 .245,-/ \mathrm{kg} ; \mathrm{BEP}(\mathrm{Q})=3.597,86 \mathrm{~kg} ; \mathrm{ROI}=78,91 \%$. Usahatani Inpari 42 : pendapatan = Rp. 10.198.685,-/ha; R/C = 1,68; $B E P(R p)=R p .2 .358,-/ k g ; B E P(Q)=3.667,93 \mathrm{~kg} ; \mathrm{ROI}=69,51 \%$. Kesimpulan : Usahatani padi varietas Inpari 32 dan varietas Inpari 42 menguntungkan dan layak secara finansial untuk diusahakan; Pendapatan dan kelayakan usahatani padi varietas Inpari 32 lebih tinggi dibanding padi varietas 42 .
\end{abstract}

Kata Kunci : Inpari 32 dan 42, kelayakan, pendapatan

\begin{abstract}
This study aims to determine the income and feasibility of farming the Inpari 32 variety and Inpari 42 variety. The study was conducted in Kutoharjo Village, Pati District, Pati Regency from May 2019 - February 2020. The research method used was a survey. The sampling method used was stratified random sampling and obtained a sample of 35 farmer respondents using the Inpari 32 variety, and 35 farmer respondents using 42. The variables calculated included the cost of seeds, fertilizers, pesticides, and labor as well as grain production. Data were analyzed using mathematical formulas for income and eligibility, and $t$-tests for differences in average income. Results: The income of Inpari 32 variety rice farming was significantly different $(P<1 \%)$ higher than Inpari 42 variety rice farming. Inpari 32 variety rice farming: income $=R p$. 11,253,124, - / ha; $R / C=1.76 ; B E P(R p)=R p .2,245,-/ \mathrm{kg} ; B E P(Q)=3,597.86 \mathrm{~kg} ; R O I=78.91 \%$. Inpari 42 Farming: income $=R p .10,198,685,-/$ ha; $R / C=1.68 ; B E P(R p)=R p .2,358,-/ \mathrm{kg} ; B E P(Q)=3,667.93$ $\mathrm{kg} ; \mathrm{ROI}=69.51 \%$. Conclusion: The rice farming of Inpari 32 and Inpari 42 varieties is profitable and financially feasible to cultivate; The income and farming feasibility of Inpari 32 variety was higher than that of 42 variety.
\end{abstract}

Keywords : feasibility, income, Inpari 32 and 42

\section{PENDAHULUAN}

Pertanian merupakan sektor yang sangat penting peranannya dalam perekonomian di Indonesia. Pembangunan sektor pertanian khususnya subsektor tanaman pangan yang merupakan salah satu penghasil bahan pangan terutama komoditas beras menjadi hal

yang sangat penting dan strategis. Disamping untuk memenuhi kebutuhan pangan, pertanian juga menampung penduduk dan memberikan kesempatan kerja bagi para petani di pedesaan. 
Kebutuhan bahan pangan utama khususnya beras setiap tahun akan semakin meningkat sesuai dengan laju pertumbuhan penduduk dan perkembangan kondisi perekonomian masyarakat. Peningkatan produksi pertanian khususnya padi merupakan salah satu upaya pemerintah dalam membangun pertanian menuju pertanian yang tangguh. Peningkatan produksi padi memegang peranan penting sebagai sumber pendapatan masyarakat petani. Sistem pertanian yang tangguh dalam pembangunan sub sekstor tanaman pangan, diarahkan untuk memenuhi kebutuhan pangan yang didukung oleh kemampuan memproduksinya.

Kabupaten Pati memiliki luas lahan seluas \pm 150.000 ha, dengan perincian : 59.299 ha lahan sawah, 60.453 ha lahan pertanian non-sawah, dan 30.755 ha lahan bukan pertanian. Kabupaten Pati merupakan salah satu kabupaten penghasil padi yang berpotensi besar di Jawa Tengah. Rizqi, A. N. (2020) melaporkan bahwa Kabupaten Pati sudah mampu memproduksi padi sebanyak 350.000 ton setiap tahunnya. Produksi ini sudah melebihi kebutuhan kebutuhan pangan di Kabupaten Pati yang hanya sebesar 150.000 ton padi setiap tahunnya.

Varietas merupakan salah satu komponen teknologi penting yang mempunyai kontribusi besar dalam meningkatkan produksi dan pendapatan usahatani padi. Komponen teknologi ini sangat berperan dalam mengubah sistem usahatani padi, dari subsistem menjadi usahatani padi komersial. Berbagai varietas unggul padi tersedia dan dapat dipilih sesuai dengan kondisi wilayah, preferensi petani, dan kebutuhan pasar. Varietas dapat didefinisikan sebagai sekelompok tanaman dari suatu jenis atau spesies tanaman yang memiliki karakteristik tertentu seperti bentuk, pertumbuhan tanaman, daun, bunga, dan biji yang dapat membedakan dari jenis atau spesies tanaman lain, dan apabila diperbanyak tidak mengalami perubahan. Jenis varietas menunjukan cara varietas tersebut dirakit dan metode perbanyakan benihnya, sehingga tersedia benih yang dapat ditanam oleh petani (Balai Besar Padi, 2015).

Beberapa jenis varietas padi telah digunakan oleh petani di Kabupaten Pati, namun sebagian petani mencoba untuk menggunakan varietas unggul baru (VUB). Triarko, K (2018) melaporkan bahwa petani di Kabupaten Pati mulai beralih menggunakan varietas bibit tanaman padi yang semula menggunakan Ciherang berganti dengan Inpari 32 HDB. Inpari 32 HDB merupakan varietas turunan Ciherang yang berumur kurang lebih 120 hari setelah semai memiliki tinggi $97 \mathrm{~cm}$, dengan postur tanaman tegak, serta daun bendera yang tegak menjulang sehingga mampu menerima dan memanfaatkan sinar matahari secara optimum untuk pertumbuhannya. Inpari 32 memiliki produktivitas yang lebih tinggi dan lebih tahan terhadap hama dibanding varietas sebelumnya. Potensi hasil Inpari 32 bisa mencapai 8,53 ton/ha Gabah Kering Giling (GKG).

Selain Inpari 32 petani Kabupaten Pati juga menggunakan bibit Inpari 42. Inpari 42 Agritan GSR merupakan jenis padi Indica (cere) hasil persilangan dari tetua Huangxinzhan/ Fenghuazhan. Umur panen varietas ini kurang lebuh 112 hari. Memiliki bentuk gabah ramping dengan tingkat kerontokan medium. Tekstur nasinya pulen dengan kadar amilosa 18,84\%. Potensi hasil hingga 10.58 ton per ha denga rata-rata hasil 7,11 ton per ha (Dinas Pertanian dan Pangan, 2020). Widodo et al.(2018) menyatakan bahwa Inpari 42 GSR memberikan produktivitas yang lebih tinggi dibanding varietas unggul baru (VUB) Inpago 5, Inpago 8, Inpago 10, Inpari 43 Agritan GSR, bahkan jauh lebih tinggi produktivitasnya dibanding dengan Ciherang. Demikian juga pendapatan dan keuntungan Inpari 42 lebih tinggi dibanding lainnya. Dengan demikian maka pemilihan varietas bibit unggul berpengaruh terhadap produksi dan pendapatan petani. 
Selain faktor varietas padi yang digunakan, peningkatan produksi padi sawah secara simultan dipengaruhi oleh banyak faktor antara lain : luas lahan, jumlah tenaga kerja efektif, dosis pupuk, dosis pestisida, pengalaman petani dalam berusahatani, jarak lahan dengan tempat tinggal petani, dan sistim pengairan (irigasi).

Tujuan penelitian ini adalah untuk mengetahui perbedaan pendapatan dan kelayakan usahatani padi varietas Inpari 32 dan varietas Inpari 42.

\section{BAHAN DAN METODE}

Penelitian dilaksanakan di Desa Kutoharjo Kecamatan Pati Kabupaten Pati dan merupakan daerah binaan dari Balai Penyuluhan Pertanian Kabupaten Pati, pada bulan Mei 2019 sampai Pebruari 2020. pengamatan memilih waktu Masa Tanam I (Bulan Oktober 2019 - Maret 2020).

Penelitian ini merupakan penelitian deskriptif, yaitu penelitian yang menyajikan gambaran lengkap mengenai fenomena petani dan dilakukan dengan survey di Desa Kutoharjo, Kecamatan Pati, Kabupaten Pati. Tujuan penelitian adalah untuk mengetahui perbedaan pendapatan dan kelayakan finansial usahatani padi yang menggunakan bibit varietas Inpari 32 dan varietas Inpari 42 . Penelitian dilakukan dengan cara survei menggunakan metode sampling Stratified Random Sampling, berdasarkan strata luas lahan kepemilikan petani. Berdasarkan hasil survei, populasi petani padi varietas Inpari 32 ada sebanyak 140 orang. Sedangkan populasi petani padi Inpari 42 juga ada sebanyak 140 orang. Jadi total populasi adalah 280 orang. Menurut Arikunto (2006) jika jumlah populasi kurang dari 100, maka seluruhnya dijadikan responden, tapi bila populasinya lebih dari 100 orang maka sampel diambil antara $10-25 \%$. Sampel diambil $25 \%$ dari total populasi ada $25 \%$ X 280 orang $=70$ orang (35 petani yang menggunakan varietas Inpari 32 dan 35 petani yang menggunakan varietas Inpari 42). Jumlah sampel masing-masing strata pada usahatani Inpari 32 dan Inpari 42 disajikan pada Tabel 1 dan Tabel 2.

Diperoleh sampel responden sebanyak 35 petani yang menggunakan varietas Inpari 32 , dan 35 petani yang menggunakan varietas Inpari 42. Teknik pengumpulan data dilakukan dengan wawancara dipandu kuesioner. Variabel yang diukur adalah semua yang berkaitan dengan pengeluaran biaya yaitu biaya benih, pupuk, pestisida, dan tenaga kerja. Penerimaan petani diperoleh dari jumlah hasil produksi dikalikan harga jual. Metode analisis yang digunakan dalam penelitian ini adalah analisis pendapatan, analisis kelayakan dengan perhitungan matematis (Suratiyah, 2016), dan analisis deskripsi yaitu analisis yang menggambarkan secara sistematik, akurat fakta dan karakteristik mengenai populasi/kegiatan yang dilakukan dalam bidang tertentu yang menjadikan subjek penelitian berdasarkan data dari variabel yang diperoleh dari kelompok subjek yang diteliti maupun fakta yang terjadi di lapangan (Nasir, 2003). Untuk mengetahui perbedaan pendapatan digunakan uji-t rata-rata pendapatan antara Inpari 32 dan Inpari 42.

\section{Pendapatan usahatani padi.}

Pendapatan usahatani padi dihitung dengan rumus sebagai berikut : (Suratiyah, K., 2016).

$$
\begin{aligned}
& I=R-C \\
& R=Y . P y \\
& I=(Y . P y)-C
\end{aligned}
$$

Keterangan :

$$
\begin{array}{ll}
\mathrm{I} & =\text { Pendapatan } \\
\mathrm{R} & =\text { Penerimaan } \\
\mathrm{Py} & =\text { Harga produksi } \\
\mathrm{Y} & =\text { Produksi Total } \\
\mathrm{C} & =\text { Biaya eksplisit total }
\end{array}
$$

\section{Uji perbedaan rata-rata pendapatan.}

Untuk mengetahui perbedaan rata-rata pendapatan usahatani padi Inpari 32 dan Inpari 42 dilakukan uji-t, yang dalam perhitungannya menggunakan aplikasi SPSS. 
Kelayakan usahatani padi (Soekartawi, 2002).

a. Kriteria usaha dikatakan layak apabila $\mathrm{R} / \mathrm{C}>1$. $\mathrm{R} / \mathrm{C}$ ratio dihitung dengan rumus

$$
\begin{aligned}
& \alpha=R: C \\
& R=Y . P y \\
& C=F C+\text { VC } \\
& \text { Keterangan : } \\
& \alpha \quad=\text { Revenue cost ratio } \\
& \mathrm{R} \quad=\text { Penerimaan } \\
& \mathrm{C} \quad=\text { Total biaya } \\
& \mathrm{Py} \quad=\text { Harga produksi } \\
& \mathrm{Y} \quad=\text { Produksi total } \\
& \mathrm{FC} \quad=\text { Biaya tetap } \\
& \mathrm{VC} \quad=\text { Biaya variabel }
\end{aligned}
$$

b. Kriteria usaha dikatakan layak apabila jumlah produksi > BEP produksi dan dapat dihitung dengan rumus :

BEP produksi $(\mathrm{kg})=$ Total Biaya Produksi : Harga Produk.

c. Kriteria usaha dikatakan layak apabila Harga > BEP harga $(\mathrm{Rp} / \mathrm{kg})$, dihitung dengan rumus:

BEP harga $(\mathrm{Rp} / \mathrm{kg})=$ Total Biaya Produksi : Jumlah Produksi

Hipotesis penelitian dapat dirumuskan sebagai berikut :

Hipotesis 1 : Diduga usahatani padi Inpari 32 dan 42 menguntungkan.

Hipotesis 2 : Diduga ada perbedaan yang nyata antara pendapatan usahatani padi Inpari 32 dengan Inpari 42.

Hipotesis 3 : Diduga usahatani padi Inpari 32 dan 42 layak secara finansial untuk diusahakan.

\section{HASIL DAN PEMBAHASAN}

\section{Analisis Pendapatan.}

Biaya merupakan pengorbanan yang dikeluarkan dalam proses produksi yang dinyatakan dengan satuan uang menurut harga pasar atau harga riil saat itu. Biaya produksi dalam usahatani padi merupakan seluruh pengeluaran untuk menghasilkan padi salam satu kali musim tanam. Biaya produksi terdiri dari biaya tetap dan biaya variable. Biaya tetap terdiri dari biaya sewa lahan dan penyusutan peralatan. Biaya variable terdiri dari biaya bibit, pupuk, pestisida, dan tenaga kerja. Penerimaan usahatani diperoleh dari penjualan hasil produksi berupa gabah dikalikan harga jual saat itu.

Pendapatan usahatani diperoleh dari penerimaan dikurangi biaya produksi. Untuk memberikan gambaran pendapatan usahatani padi dilakukan perhitungan per luas lahan riil yang dimiliki petani dan pendapatan usahatani padi dengan dikonversikan ke dalam 1 (satu) hektar luas lahan.

Rekapitulasi hasil perhitungan biaya, penerimaan, dan pendaatan usahatani padi Inpari 32 dan Inpari 42 disajikan pada Tabel 3.

Biaya merupakan sejumlah pengorbanan yang perlu dikeluarkan untuk proses produksi. Penerimaan tergantung pada besar hasil produksi dan harga produk saat itu. Secara umum dapat dikatakan bahwa semakin besar biaya produksi yang dikeluarkan akan mengurangi pendapatan usahatani apabila tidak diimbangi dengan kenaikkan produksi yang siknifikan. Berdasarkan Tabel 3 . diperoleh bahwa dari aspek biaya produksi, usahatani yang menggunakan bibit padi Inpari 32 biaya produksi yang dikeluarkan lebih rendah dibanding dengan biaya produksi yang menggunakan bibit Inpari 42. Biaya produksi padi varietas Inpari 32 sebesar Rp. 14.391.447,-, sedangkan padi varietas Inpari 42 sebesar Rp. 14.671.726,-/ha. Sebaliknya hasil produksi usahatani yang menggunakan bibit padi varietas Inpari 32 hasilnya relatif lebih besar dibanding Inpari 42. Produksi padi Inpari 32 sebesar $6.411,14 \mathrm{~kg} / \mathrm{ha}$, sedangkan Inpari 42 sebesar $6.217,60 \mathrm{~kg} / \mathrm{ha}$. Terdapat selisih sebesar 193,54 kg per hektar. Dengan harga jual gabah yang sama sebesar Rp.4.000,-/kg maka diperoleh hasil bahwa pendapatan usahatani padi Inpari 32 lebih tinggi dibanding dengan padi Inpari 42. Ma'ruf et al. (2019) menyatakan bahwa secara umum, peningkatan produksi suatu usahatani merupakan indikator keberhasilan dari usahatani yang bersangkutan, namun tingginya produksi suatu komoditas yang 
diperoleh dalam per satuan luas lahan belum menjamin tingginya pendapatan usahatani padi sawah yang dipengaruhi oleh harga yang diterima petani dan biaya-biaya penggunaan input usahatani.

Pada penelitian ini diperoleh hasil produksi padi Inpari 32 sebesar 6.411,14 $\mathrm{kg} / \mathrm{ha}$. Hal ini melebihi dibanding dengan deskripsi varietas Inpari 32 yang menyatakan bahwa produksi rata-rata inpari 32 sebesar 6,3 kg/ha yang dikeluarkan oleh Balai Penelitian dan Pengembangan Pertanian (2019). Sedangkan produksi padi Inpari 42 diperoleh $6.217,6 \mathrm{~kg} / \mathrm{ha}$. Hal ini lebih rendah disbanding dengan deskripsi varietas Inpari 42 yang menyatakan bahwa produksi ratarata padi Inpari sebesar $7,11 \mathrm{t}$ In/ha (Balai Besar Padi, 2019). Perbedaan tingkat produksi ini diduga bahwa Inpari 32 lebih cocok diusahakan pada daerah penelitian atau sebaliknya varietas Inpari 42 kurang cocok diusahakan pada daerah tersebut. Faktor lingkungan yang berpengaruh terhadap produksi antara lain : suhu, struktur tanah, jenis tanah, dan $\mathrm{pH}$ tanah. Wahyuni et al. (2013) dalam penelitiannya menyatakan bahwa hasil gabah ditentukan oleh sifat genetic dari varietas yang ditanam dan kondisi agroekologis. Wulandari dan Sudrajat (2017) menyatakan bahwa aspek lingkungan berupa kondisi cuaca dan iklim, perawatan hama dan penyakit, dan kondisi lainnya seperti air, tanah dan lain-lain berperan penting dalam kegiatan usahatani. Sedangkan Darwati dan Noeriwan (2019) menyampaikan hasil bahwa produksi varietas Inpari 42 lebih tinggi dibanding inpari 32 dan jauh lebih tinggi dibanding Ciherang. Ratnawati et al. (2019) menyatakan rata-rata produksi padi Inpari 42 sebesar 7,11 ton/ha. Kondisi lingkungan tumbuh yang sesuai cenderung merangsang proses inisiasi malai menjadi sempurna, sehingga peluang terbentuknya bakal gabah menjadi lebih banyak. Namun demikian semakin banyak gabah yang terbentuk, meningkatkan beban tanaman untuk membentuk gabah bernas. Apabila saat proses pengisian gabah, tidak diimbangi dengan ketersediaan hara yang mencukupi akan banyak terbentuk gabah hampa. Persentase gabah isi merupakan salah satu indikator produktivitas tanaman, semakin tinggi persentase gabah isi yang diperoleh suatu varietas menandakan varietas tersebut mempunyai produktivitas yang tinggi.

\section{Analisis Uji Beda Rata-rata Pendapatan Usahatani varietas Inpari 32 dan Varietas Inpari 42.}

Untuk mengetahui apakah ada perbadaan yang nyata antara pendapatan usahatani yang menggunakan padi Inpari 32 dan padi Inpari 42, maka dilakukan uji-t. Hasil olah data Uji beda rata-rata pendapatan disajiakan pada Tabel 4.

Tabel 4. menunjukkan bahwa hasil uji beda rata-rata pendapatan antara kedua padi Inpari 32 dan Inpari 42 berbeda sangat nyata. Rata-rata pendapatan usahatani Inpari 32 sebesar Rp. 11.253.124,- / ha lebih tinggi dibanding rata-rata pendapatan usahatani Inpari 42 sebesar Rp. 10.198.685,-/ha. Perbedaan pendapatan ini disebabkan karena hasil produksi Inpari 32 lebih besar dibanding dengan hasil produksi Inpari 42. Hal ini disebabkan karena perbedaan kemampuan genetik pada varietas tersebut. Disamping perbedaan genetik, juga disebabkan pengaruh kondisi lingkungan tumbuh. Wahyuni et al. (2010) melaporkan bahwa hasil gabah kering panen (GKP) sangat dipengaruhi oleh kesesuaian varietas yang ditanam, keberadaan dan keparahan serangan hama penyakit dan kondisi lingkungan tumbuh yaitu ketersediaan air, pemupukan yang sesuai, kerebahan tanaman karena angin.

\section{Analisis Kelayakan}

Kelayakan dari suatu usahatani adalah penelitian yang dilakukan secara mendalam bertujuan untuk menentukan apakah usaha yang dijalankan akan memberikan manfaat yang lebih besar dibanding dengan biaya yang dikeluarkan. Kelayakan dapat diartikan bahwa usaha yang dijalankan akan memberikan keuntungan finansial dan non 
finansial sesuai dengan tujuan yang diinginkan.

Rekapitulasi hasil perhitungan kelayakan usahatani padi Inpari 32 dan Inpari 42 disajikan pada Tabel 5.

Berdasarkan Tabel 5. diperoleh hasil bahwa secara umum usahatani padi Inpari 32 dan Inpari 42 sama-sama layak secara finansial untuk diusahakan. Hal ini ditunjukkan dengan nilai $\mathrm{R} / \mathrm{C}>1$. Namun usahatani padi pengguna Inpari 32 mempunyai tingkat kelayakan yang lebih tinggi dibanding dengan pengguna Inpari 42. Nilai kelayakan usahatani Inpari $32(R / C=1,76)$ yang lebih besar dibanding Inpari $42(\mathrm{R} / \mathrm{C}=1,68)$ disebabkan karena hasil produksi padi Inpari 32 lebih besar dibanding produksi padi Inpari 42 sehingga pendapatan Inpari 32 lebih besar disbanding Inpari 42. Selisih produksi padi

\section{DAFTAR PUSTAKA}

Arikunto, S. 2006. Prosedur Penelitian Suatu Pendekatan Praktek. Rineka Cipta, Jakarta.

Balai Besar Padi. 2015. Pengertian Umum Varietas, Galur, Inbrida, dan Hibrida. http://bbpadi.litbang.

pertanian.go.id/index.php/info-

berita/info-teknologi/pengertian-

umum-varietas-galur-inbrida-dan-

hibrida. Diakses 9 Nopember 2020.

Balai Penelitian dan Pengembangan Pertanian. 2019. http://www.litbang.pertanian. go.id/varietas/1024/. Diakses tgl. 9 Nop 2020.

Darwati, E. dan Noeriwan. 2019. Keragaan hasil VUB padi Inpari 42, 43, 32 dan varietas existing Ciherang di $\mathrm{Kp}$. Mojosari. Prosiding Temu Teknis Jabatan Fungsional Non Peneliti, hal. 363-369.

Ma'ruf, M. I., C. A. Kamaruddin, dan A. Muharief. 2019. Analisis Pendapatan dan Kelayakan Usahatani Padi di sebesar 121,26 kg/ha. Sedangkan apabila dilihat dari besar biaya produksi selisihnya tidak besar hanya Rp. 153.890,- Demikian juga nilai kelayakan BEP dan ROI inpari 32 lebih baik dibanding dengan Inpari 42.

\section{SIMPULAN}

Berdasarkan hasil penelitian pada usahatani padi Inpari 32 dan Inpari 42 di Desa Kutoharjo, Kecamatan Pati Kabupaten Pati dapat ditarik kesimpilan sebagai berikut :

a. Terdapat perbedaan yang sangat nyata $(P<1 \%)$ rata-rata pendapatan usahatani padi varietas Inpari 32 dengan varietas Inpari 42. Pendapatan usahatani padi varietas Inpari 32 lebih besar dibanding varietas Inpari 42.

b. Kelayakan usahatani padi varietas Inpari 32 lebih tinggi dibanding dengan varietas Inpari 42.

Kecamatan Pitu Riawa Kabupaten Sidrap.

Nazir, M. 2013. Metode Penelitian. Bogor: Ghalia Indonesia.

Ratnawati, Alfandi, dan I. Sungkawa. 2019. Respon Pertumbuhan Tanaman dan Hasil Beberapa Varietas Padi Sawah Tadah Hujan (Oryza sativa, L.) Akibat Penerapan Teknologi. J. AGROSWAGATI, Vol. 7, No. 2, Oktober 2019. file:///C:/Users/User /Downloads/2800-7499-1-SM.pdf. Diakses tgl. 14 Nopember 2020.

Rizqi, A. N. (2020) Pati Produksi 350.000 Ton Padi, 43 Persen untuk Kebutuhan Lokal.

https://semarang.bisnis.com/read/202 00715/536/1266335/pati-produksi350.000-ton-padi-43-persen-untukkebutuhanlokal\#: :text=Wakil\%20Bupati\%20Pat i\%2C\%20

Syaiful\%20Arifin,Pati\%20150.000\%2 Oton\%20setiap\%20tahun. Diakses tgl 6 Nopember 2020. 
Agrisaintifika

Jurnal Ilmu-Ilmu Pertanian

Vol. 5, No. 1, 2021

Saparto, et al. 2021

Soekartawi. 2002. Analisis Usahatani. Jakarta: Penerbit Universitas Indonesia (UI-Press).

Suratiyah, K., 2016. Ilmu Usahatani. Jakarta : Penebar Swadaya.

Triarko, K. 2018. Bibit Padi Inpari Disukai Petani Pati. https://www.cendananews .com/ 2018/02/bibit-padi-inpari-disukai-

petani-pati.html. Diakses tgl 6 Nopember 2020.

Widodo, S., B. Sutaryo, dan D. Riyanto. 2018. Kajian Sosial Ekonomi Beberapa Varietas Unggul Baru Padi di Lahan Sub-Optimal Gunung Kidul, Yogyakarta. Prosiding Seminar Nasional Lahan Suboptimal 2018, Palembang 18-19 Oktober 2018 : "Tantangan dan Solusi Pengembangan PAJALE dan Kelapa Sawit Generasi Kedua (Replanting) di Lahan Suboptimal”. Hal. 456-464.
Wahyuni, S., I. W. Mulsanti, dan Rasam. 2010. Hasil Gabah dan Komponen Hasil Padi dari

Pertanaman dengan Empat Kelas benih yang Berbeda pada Lima Varietas Padi Populer.

Laporan Hasil Penelitian. 2009. Balai Besar Penelitian Tanaman Padi. Jawa Barat.

Wahyuni, S., I.W. Mulsanti, dan Satoto. 2013. Produktivitas Varietas Padi dari Kelas Benih Berbeda. J. Iptek Tanaman Pangan. Vol.8, No.2, Th 2013. http://pangan.litbang. pertanian.go.id/files/02-

SriWahyunilT0802.pdf. Diakses tgl. 14 Nopember 2020.

Wulandari, N. S., dan Sudrajat. 2017. Preferensi Petani Dalam Menentukan Varietas Benih Padi di Desa Pablengan Kecamatan Matesih Kabupaten Karanganyar. Jurnal Bumi Indonesia. Volume 6, Nomor 4 Tahun 2017.

\section{Lampiran}

Tabel 1. Banyaknya Sampel Pada Masing-masing Strata Inpari 32

\begin{tabular}{|c|c|c|c|}
\hline Strata & $\begin{array}{c}\text { Luas } \\
\text { (ha) }\end{array}$ & Populasi & Sampel \\
\hline 1 & $0,300 \mathrm{~s} / \mathrm{d} \quad 0,860$ & 100 & 25 \\
\hline 2 & $0,861 \mathrm{~s} / \mathrm{d} \quad 1,420$ & 32 & 8 \\
\hline 3 & $1,421 \mathrm{~s} / \mathrm{d} 2,000$ & 8 & 2 \\
\hline & umlah Sampel & 140 & 35 \\
\hline
\end{tabular}

Sumber : Data Primer, diolah 2019

Tabel 2. Banyaknya Sampel pada Masing-masing Strata Inpari 42

\begin{tabular}{|c|c|c|c|}
\hline Strata & $\begin{array}{c}\text { Luas } \\
(\mathrm{Ha})\end{array}$ & Populasi & Sampel \\
\hline 1 & $0,200 \mathrm{~s} / \mathrm{d} \quad 0,800$ & 104 & 26 \\
\hline 2 & $0,801 \mathrm{~s} / \mathrm{d} \quad 1,400$ & 28 & 7 \\
\hline 3 & $1,401 \mathrm{~s} / \mathrm{d} 2,000$ & 8 & 2 \\
\hline & umlah Sampel & 140 & 35 \\
\hline
\end{tabular}

Sumber : Data Primer, diolah 2019 
Agrisaintifika

Jurnal Ilmu-Ilmu Pertanian

Vol. 5, No. 1, 2021

Saparto, et al. 2021

Tabel 3. Rekapitulasi Biaya, Penerimaan, dan Pendapatan Usahatani Padi Inpari 32 dan Inpari 42 per Rata-rata Luas Lahan dan per Hektar.

\begin{tabular}{|c|c|c|c|c|c|}
\hline \multirow[t]{3}{*}{ No } & \multirow[t]{3}{*}{ Uraian } & \multicolumn{2}{|c|}{ Inpari 32} & \multicolumn{2}{|c|}{ Inpari 42} \\
\hline & & Jumlah (Rp) & Jumlah (Rp) & Jumlah (Rp) & Jumlah (Rp) \\
\hline & & per 0,71 ha & per 1,00 ha & per 0,71 ha & per 1,00 ha \\
\hline \multirow[t]{3}{*}{1} & Biaya Tetap : & & & & \\
\hline & Sewa lahan & 3.448 .380 & 4.872 .365 & 3.454 .714 & 4.917 .643 \\
\hline & Total Biaya Tetap & 3.448 .380 & 4.872 .365 & 3.454 .714 & 4.917 .643 \\
\hline \multirow[t]{5}{*}{2} & Biaya Variabel: & & & & \\
\hline & a. Bibit & 325.700 & 449.952 & 331.334 & 468.512 \\
\hline & Pupuk & 2.456 .653 & 3.416 .333 & 2.532 .106 & 3.453 .411 \\
\hline & Pestisida & 798.423 & 1.109 .275 & 820.871 & 1.168 .446 \\
\hline & d. Tenaga Kerja & 3.228 .358 & 4.543 .522 & 3.272 .400 & 4.663 .714 \\
\hline 3 & Total Biaya Variabel & 6.809 .134 & 9.519 .082 & 6.956 .691 & 9.754 .083 \\
\hline 4 & Total Biaya Produksi & 10.257 .515 & 14.391 .447 & 10.411 .406 & 14.671 .726 \\
\hline \multirow[t]{3}{*}{5} & Penerimaan: & & & & \\
\hline & a. Hasil $(\mathrm{kg})$ & $4.513,13$ & $6.411,14$ & $4.391,87$ & $6.217,60$ \\
\hline & b. Harga GKP & 4.000 & 4.000 & 4.000 & 4.000 \\
\hline 6 & Total Penerimaan & 18.052 .514 & 25.644 .571 & 17.567 .465 & 24.870 .411 \\
\hline 7 & Pendapatan & 7.794 .999 & 11.253 .124 & 7.156 .059 & 10.198 .685 \\
\hline
\end{tabular}

Tabel 4. Analisis Uji Beda Rata-rata Pendapatan Usahatani Padi Pengguna Inpari 32 dan Pengguna Inpari 42.

\begin{tabular}{lccccc}
\hline & Varietas & Rata-rata $(\mathrm{Rp})$ & $\mathrm{t}$ & $\mathrm{df}$ & Sig (2 tail) \\
\hline Pendapatan & Inpari 32 & 11.253 .124 & 10,76 & 68 & 0,000 \\
& Inpari 42 & 10.198 .685 & & & \\
\hline
\end{tabular}

Sumber : Data Primer Penelitian, 2020

Tabel 5. Hasil Kelayakan Finansial Usahatani Padi Inpari 32 dan Inpari 42 per Hektar

\begin{tabular}{cccc}
\hline No & Uraian & Inpari 32 & Inpari 42 \\
\hline 1 & Penerimaan (Rp) & 18.052 .514 & 17.567 .465 \\
2 & Total Biaya Produksi (Rp) & 10.257 .515 & 10.411 .405 \\
3 & Pendapatan (Rp) & 7.794 .999 & 7.156 .059 \\
4 & Produksi Riil (kg) & $4.513,13$ & $4.391,87$ \\
5 & Harga GKP Riil (Rp/kg) & 4.000 & 4.000 \\
6 & $\mathrm{R} / \mathrm{C}$ & 1,76 & 1,68 \\
7 & $\mathrm{BEP}_{\mathrm{Q}}(\mathrm{kg})$ & $2.564,38$ & $2.602,85$ \\
8 & BEP $_{\mathrm{Rp}}(\mathrm{Rp})$ & 2.245 & 2.359 \\
9 & $\mathrm{ROI}(\%)$ & 75,99 & 68,73 \\
\hline
\end{tabular}

Sumber : Data Primer Diolah (2020) 